Boise State University

ScholarWorks

Counselor Education Faculty Publications and

Presentations

Department of Counselor Education

$1-1-2016$

\title{
School Counselors' Experiences Working with Digital Natives: A Qualitative Study
}

Laura L. Gallo

Boise State University

Meredith Rausch

Augusta University

Carol Klose Smith

University of Iowa

Susannah Wood

University of Iowa 


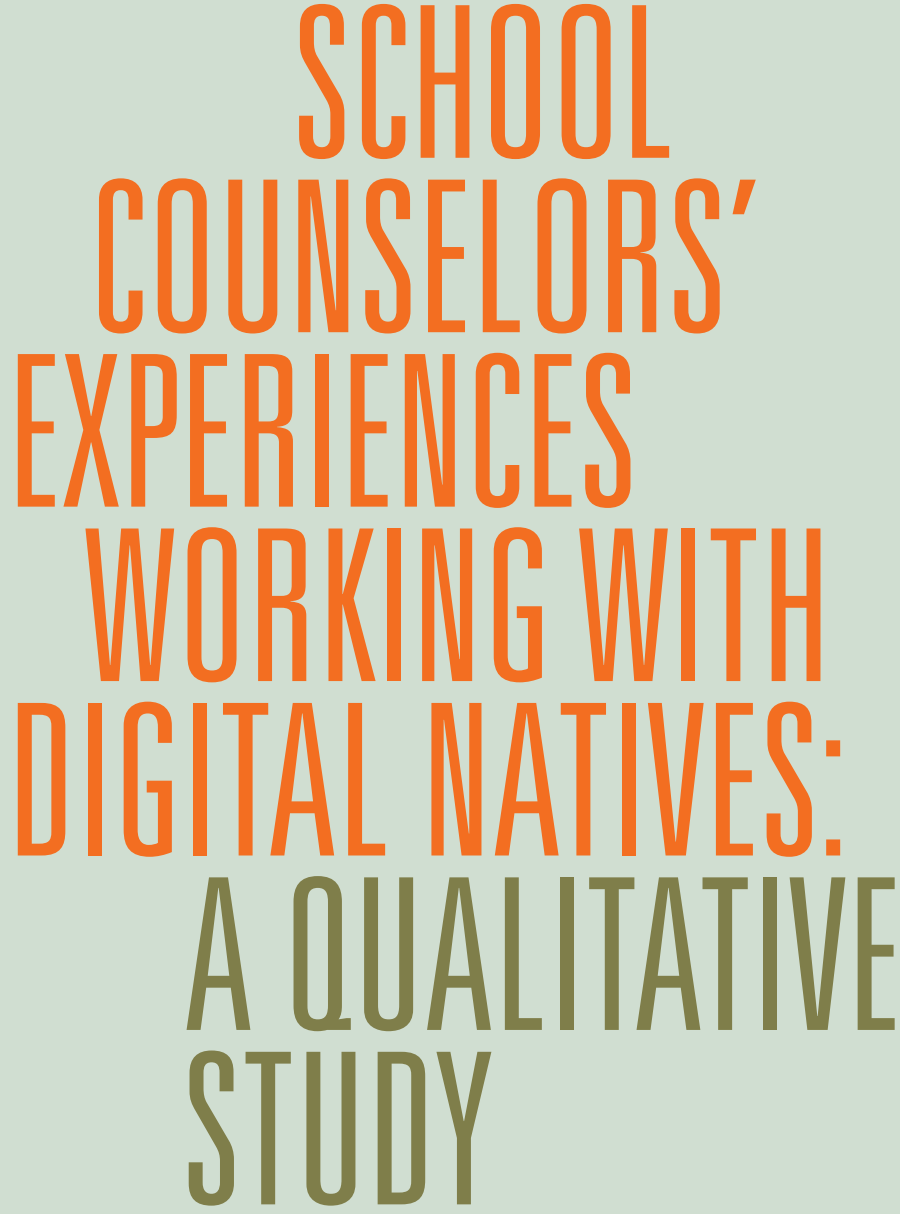

To better understand school
counselors' experiences related to
students' use of social media, the
authors conducted a qualitative
study, utilizing a phenomenological
approach, with eight practicing
high school counselors. Three
major themes emerged from
the study: "the digital cultural
divide," "frustration and fear," and
"embracing change." This article
presents implications for school
counseling practice and research.

\begin{abstract}
oung people are constantly connected to one another through technology (Palfrey \& Gasser, 2008). A staggering 92\% of American teens use the Internet daily as an important venue for social interaction (Lenhart, 2015). Cell phones have become the primary communication hub for American teens, with $88 \%$ having access to phones and $90 \%$ of those sending text messages (Lenhart, 2015). Seventyone percent of teens are using social networking sites and the majority of online teens are using more than one social media site (Lenhart, 2015).

Teens are communicating more often and more quickly than previous generations, and are using photos and video as well as written language to communicate (Lenhart, Madden, \& Hitlin, 2005).

According to the American School Counseling Association (ASCA), "professional school counselors promote the responsible use of technology in collaboration with families and educators to increase student safety" (ASCA, 2012, p. 53). School counselors also have an ethical responsibility to protect their students and safeguard them from harm (ASCA, 2010), which includes harm done through the use of technology. School counselors must be concerned and well informed not only about cyberbullying, but cyberstalking, students' posting inappropriate pictures online, sending inappropriate content via text message, or posting
\end{abstract}

Laura L. Gallo, Ph.D., NCC, LPC, is an assistant professor in the Department of Counselor Education at Boise State University in Boise, ID. E-mail: lauragallo@boisestate.edu Meredith Rausch, Ph.D., NCC, is an assistant professor at Augusta University in Augusta, GA. Carol Klose Smith, Ph.D., is a clinical associate professor and Susannah Wood, Ph.D., is an associate professor, both with the College of Education at the University of lowa.

doi: 10.5330/1096-2409-20.1.14 
illegal activities on social media sites (Barrett, 2006; Oriji \& Efebo, 2013). Furthermore, school counselors must recognize that adolescents may not yet fully understand the digital footprints they are leaving behind (Quitney \& Rainie, 2010; Barrett, 2006). Thorny issues such as responsible use of technology at school (versus at home), texting, cyberbullying, and social media leave many educators wondering how to help their students who understand more about social media and digital connections than they do.

Marc Prensky (2001) coined the term digital native to refer to this newly technologically connected generation. Palfrey and Gasser (2008) wrote:

For these young people, new digital technologies, computers, and cell phones are primary mediators of human-to-human connections. They have created a continuous network that blends human with technical to a degree we haven't experienced before, and it is transforming human relationships in fundamental ways (p. 4-5).

In addition to digital natives, Palfrey and Gasser (2008) identified digital settlers, or those who lived in the analog world but helped usher in a new technological era through tools like the World Wide Web, cell phones, digital cameras, and downloadable music. They also refer to digital immigrants, or those who remember and still use nondigital tools such as handwritten letters but who can also use digital technology (Palfrey \& Gasser, 2008). While opinions may differ, these authors assert that most school counselors fall into the category of digital immigrants, who feel human relationships are second nature but for whom utilizing and thriving in an increasingly digital world is a learned behavior (Palfrey \& Gasser, 2008). Thus, in order to reach digital natives, digital immigrants continue to adapt their communication and teaching styles to effectively interact with this new wave of learners.

\section{NOWE OF THE PARTILIPANTS GREW UP WITH THE INTERMET, WHEREEAS THEEIR STUDENTS HAVE ALWAYS LIVED ... SURROUNDED BY TECHNOLOGY AND VARIOUS SOCIAL MEDIA OUTLETS.}

Issues related to the digital world are commonplace in our society and the educational system is lagging behind in helping children become responsible digital citizens (Giedd, 2012). Understanding how school counselors are experiencing this phenomenon is important, but little research has been conducted regarding school counselors' degree of familiarity and comfort with digital technology, nor their interactions with their digital native students. The purpose of this study was to explore and gain a deeper understanding of the experiences of high school counselors working with the digital native population.

The following research question guided the current study: What are the experiences of school counselors working with digital natives and digital technology? The authors suggest that the concept of experience is a broad one, especially in light of school counselors' multiplicity of roles and functions. For the purpose of this study, experiences include school counselors' professional experiences (e.g., their use of digital technology for work-related responsibilities). Professional experiences can, and should, include their interactions with their digital native students, their families, and other stakeholders such as administrators, school board members, and resource officers. The authors also understand that school counselors' personal experiences (e.g., their use of digital technology on their own time) could transfer over into their professional life and therefore also acknowledge these experiences.

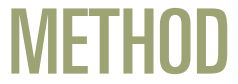

To provide insight into the essence of school counselors' experiences, this study's authors used qualitative research utilizing a phenomenological approach. This study is largely exploratory; therefore, qualitative interviews were a good way to understand the personal experiences of the target population. A semistructured interview format was used with all participants to provide some consistency between interviews while allowing each participant the opportunity to share new perspectives that may not have been asked about directly.

\section{Participants}

The study was conducted with eight practicing high school counselors, five of whom were female and three of whom were male. Each counselor had more than five years of experience and worked in buildings with students in grades 9-12. All of the school counselors worked in public high schools in the Midwestern United States, with enrollment ranging from 500 to 2000 students. All of the school counselors held master's degrees and were certified to practice school counseling within their states of residence. Participants were recruited through an initial email sent by the first researcher (also a practicing high school counselor). She sent approximately 15 initial e-mails. Six counselors expressed interest in participating and were sent a copy of the informed consent and encouraged to ask questions prior to agreeing to participate. Six of the eight participants were recruited from this initial email. Following the interview, the author used snowball sampling to provide a greater pool of potential participants and the final two participants were recruited from this method (Patton, 2002). 
Instruments and Procedures

The same researcher conducted all of the semistructured interviews to help maintain consistency throughout the study. The questions were developed by the first author based on a review of the literature on adolescents and their use of digital technology. The semistructured interview process was used to provide some structure to the interview and to help provide direction (Englander, 2012) while also allowing new information to emerge. The 10 semistructured interview questions were asked of each participant, with the opportunity for the researcher to elaborate and ask additional questions based on answers provided by the interviewees (see Appendix). tion, the lead author completed two additional interviews. These final two interviews did not produce novel information. The three researchers determined that no additional interviews were needed for the study.

\section{Data Coding and Analysis}

The researchers analyzed the data using inductive analysis (Patton, 2002).

This type of analysis allows a researcher to consistently review transcripts while examining emerging themes (Patton, 2002). The research team chose specifically to analyze the data in this manner in an effort to understand the digital native phenomenon as a whole unit (Patton, 2002). Each interview was transcribed and mem-

\section{"I SEE A LOT OF KIDS THAT HAVE NO CONCEPT OF DELAYED GRATIFICATION AND TECHNOLOGY ... DEFINITELY FEEDS INTO IT."}

The lead author contacted potential participants through e-mail and sent a letter of information. She made arrangements with participants regarding the time and place to meet. All interviews were conducted in person at a private location after school hours. At the beginning of each interview, the researcher asked if the participant had any questions regarding the purpose of the study, confirmed that the participant had read the letter of information, and thanked them for participating. At the conclusion of each interview, the researcher informed the participant that they would be receiving a transcription of the interview to read over and clarify if there were any errors. All participants were reassured that any identifiable information would be eliminated from the study (school names, mascots, etc.).

After the sixth interview, the authors determined that theoretical saturation had been reached. No new categories were formed and no new information emerged upon the completion of the sixth interview. To assure satura- ber-checked prior to the data analysis process. The data analysis process consisted of several steps. The second and third research team members reviewed and coded all interviews. Discussion concerning coding continued until agreement for all codes was reached between the team members. Striving for intercoder agreement between the researchers helps the reliability of qualitative research (Creswell, 2013). The finalized codes were organized into categories and then into themes.

The transcripts, coding, categories and themes were then reviewed by the first author for internal homogeneity and external heterogeneity. This process involved reviewing the categories for meaning and differences of categories and themes (Patton, 2002). Due to the lead researcher's involvement in the interview process, the team selected her to review the final categories and themes to insure accuracy and placement (Patton, 2002). Involving all three research members in reviewing findings was an important feature of the study. Using analyst triangula- tion enhances quality and credibility of qualitative research (Patton, 2002). Once the research team reached consensus, the team selected quotations from the transcripts that best represented the emerging themes, and thus, the phenomenon as a whole.

\section{Trustworthiness}

To enhance trustworthiness of the data, several strategies were employed. First, member checking was completed within one week of each interview. Participants had the opportunity to review interview transcripts and respond with corrections or clarifications. All eight of the participants responded to the request for member checking, and three participants made clarifications and corrections to the transcripts. Second, to capture the essence of the participants' experiences, participants' own words were used when describing emerging themes.

The third strategy involved researchers bracketing their assumptions and biases before beginning the study (Creswell, 2014). Members of the research team used peer debriefing throughout the investigation to minimize bias when analyzing data and discussing results. Research team members were cognizant of their original biases and assumptions and consulted with each other to help mediate these effects. Brief descriptions of the research team member's assumptions are presented below.

The first author was a doctoral student and a practicing school counselor at a high school in the Midwest, and this study grew out of her interest in understanding the effects social media has on adolescents' development. Her assumptions before beginning this study included: a) high school counselors often discuss issues related to digital technology and the impacts of technology with their students, b) not all school counselors have experience with forms of digital technology (e.g., Facebook, Twitter, MySpace), and c) school counselors do not regularly receive opportunities for professional development in the area of digital technology. Her assumptions about 
digital natives were that students' experiences with social media were disruptive to the school environment, and she feared that social media caused a lot of stress and grief for adolescents. This researcher was curious to learn what types of experiences other high school counselors were having with the students in their schools involving social media.

The second researcher believed that adolescents will participate in more emotionally charged communication through digital technology, thus limiting the communicative development for this group. This slowed development would lead to lesser availability of developed coping strategies, and diminishing levels of patience as the need for instant gratification and consistent stimulation grows.

The third researcher believed that her views are affected by her experiences prior to the onset of digital native culture, as well as being the parent to two digital natives. Her assumptions include the idea that many digital natives have a natural intuitive ability with electronics that far surpasses her knowledge. She also felt that this population is often preoccupied with electronic communication, sometimes at the expense of face-to-face communication.

FINDINGS

The purpose of the study was to better understand the experiences of school counselors working with digital natives. Three themes emerged from the interviews to describe the school counselors' experiences in working with students immersed in digital technology. These three themes were the digital cultural divide, frustration and fear, and embracing change. The three themes and relevant subthemes are presented and discussed below.

\section{Theme 1: The Digital Cultural Divide}

The first theme to emerge, the digital cultural divide, related to the gap that exists between the school counselors and their students relative to their understanding of and immersion in digital technology. None of the participants grew up with the Internet, whereas their students have always lived with the Internet and in a world surrounded by technology and various social media outlets. Two subthemes emerged from this theme: utilitarian use of technology and instant gratification. they put out about themselves.. and...I don't grasp that in my head and it makes me feel old. But to them, it's a cultural thing that... and especially the teenagers now, it's always been there? They don't know any different.

The participants believed students were also more likely to use technol-

\section{THE ABILITY TO SELF-XXPRESSS ALSO COMES WITH CONSEQUENCES, MANY OF WHICH ARE PERMAWENT.}

Utilitarian use of technology. Although school counselors in this study reported that they did have both personal and professional experience with digital technology, the emphasis was on the utilitarian use of the technology and how it enhanced their work, including developing and managing school counseling program websites and e-newsletters, and utilizing Twitter feeds and e-mail as methods of communication and dissemination of information. Participant Four said, "I would say I'm an avid user, not an advanced user but I like technology and I use it to make my life easier, that's really the only reason I use technology is to make my life easier."

Although school counselors articulated utilizing technology from a practical, utilitarian standpoint, they saw that their students engaged with digital technology in a very different way. Students' interaction with technology is very much a fundamental part of their world. As one participant stated, "It's a lot more...it's almost woven into their lives to such an extent that it's almost the question is 'what isn't a part of social media?"'

Several participants discussed their perspectives on this unique aspect of student "culture" and described in detail what they believed was the digital native culture. Participant Four said:

Like I said, I almost feel like it's a cultural...like I'm not 18 anymore, it wasn't around when I was there and even the stuff that ogy as an expressive outlet. Participants Six and Eight discussed the benefits of social media for students who typically had little voice, or who were naturally introverted. In their experience, these students were more likely to reach out to them or to others via e-mail or Facebook. Other students utilized social media like Facebook or blogging similarly to writing poetry or handwritten journals. Participant Eight stated:

Sometimes it's ok to put things out there...maybe that's your way of journaling to make yourself feel better, or maybe that person didn't have a voice before because they couldn't get it out there, they didn't have the guts to put it out there... now maybe they have a voice to say that they've been hurt or something like that...that part's ok.

Instant gratification. The second subtheme related to a difference between digital native culture and the participants, one that participants saw as an aspect of being surrounded by technology. Participant Six described this important aspect of digital native culture as "immediacy of information."

You know I think that's [their] culture. And that, you know, we have been in that culture and it's the immediacy of information and for me to either find information and be able to assist the student 
...compared to...in the past when

I started so go back to '93-'94 and

"Hey can you help me find some information?" so, yeah, it's either in a book form or something to pull out from the file.

All participants discussed how the immediacy of information and instantaneous feedback from social media sites and texting created a part of the digital native culture, which one participant coined the "culture of expectations."

But, ok, if I have a question at 7 o'clock at night, am I presuming [the counselor] is online at 7 o'clock at night to answer that? No...no, that should not be the case. But it creates that culture because kids panic, 'cause at night kids are like, "Oh, I tried to e-mail you [the counselor] that information and, you know I didn't get back to you, and so if I miss that deadline..." but I just think that creates this culture that you're available...24/7 as well.

Participants described how students would send them e-mails from their phones during class periods and worried that students who could not delay their gratification would run into problems later if they didn't hear what was said in a lecture or if projects or tests required more studying. Participant Two said:

I see frustration boil over really fast if, "Well, I studied for this test for 10 minutes and how come I got a D on it?" Well, you're not going to just get an A on your test as fast as you're gonna pull up Google, it's not, it doesn't work that way.
Participants Two and Five also worried that if students were not able to discipline themselves to not be by their phone or their computer that this would impact their future careers. Participant Five said:

So, it's a distraction and kids will have to learn that eventually, how to manage their time and learn how to be productive in college and the workforce, so I think its ok that they're having to learn how to function, but we're having a lot of issues where kids aren't handling that well.

Some participants wondered whether the continuous state of "being plugged in" bordered for some students on addiction or compulsion, which might impact students' psychological well-being. One participant said:

I see a lot of kids that have no concept of delayed gratification and technology makes that maybe not worse, but it definitely feeds into it. And so I can't get a kid to give up their cell phone for a class period. And, and they can't put it, I think they actually cannot put it away, there's some compulsion there where they have to constantly be looking at it, checking it, etc.

The constant state of being plugged in was and is, according to several of the participants, detracting from students' abilities to communicate effectively with one another. Participant Seven said with regard to students, "The hallways and the cafeteria have been quickly changed to, 'Oh, he broke up with me over text.' 'They threaten me, they're going to jump me at lunch.' Those things have irrevocably changed from social media."

\section{"WHAT THEY CAN SAY BEHWND THE SCREEN OF A TEXT WITHOUT LOOKING INTO SOMEBODY'S EYES IS FAR MORE detrimental than It EVER cOULd be FaCE To FaCE."}


and so...if people make mistakes on something, it's being put back in their face and they're trying to make it better and they're trying to do things the right way next time, they're still having something that happened a year ago thrown back in their face, when things don't go their way.

These participants feared that some students simply didn't have either the technical savvy not to erase their digital footprint or the impulse control to curtail their personal sharing through social media or text. Participant Four said:

Like I said, a lot of the Facebook stuff has kind of slimmed down but protecting kids' privacy, I mean what they would share with somebody they don't know...or never met. That is very scary to me and I guess frustrating. That they believe they're so young and innocent that they just don't and especially some that may be lower skilled students that have access to technology but just really I feel like get taken advantage of.

Shrouds kids wear. Many of the participants believed that the anonymity that the social media and digital technology accounts provided enabled students to write and communicate things that they would not normally say if they were face to face with another person. Participant One called this the "shroud kids wear" while Participant Three called it "cowardice behind media." Participant Seven said:

I find it as a very...just say, cowardly way to do a lot of things. And what they can say behind the screen of a text without looking into somebody's eyes is far more detrimental than it ever could be face to face because they wouldn't have the courage to do it otherwise.

Participant Three added, "and you can always 'unpost' or you know, take

\section{MOST PARTILIPANTS TALKED ABOUT THE "BLEED OVER" BETWEEN ONLLWE EXCHANGES THAT HAPPENED OFF OF SCHOOL PROPERTY BUT BECAME PART OF THE STUDENTS' LIVES IMMEDIATELY AFTERWARDS.}

it off, but it has been out there now and now it exists in people's lives so... that's frustrating." Participant Four worried that with the anonymity facilitating student expression, including expression of sexuality, students were unaware of the provocative and potentially detrimental effect of the screen names they chose. Participant Four discussed this point, remarking:

Students who-their Twitter name is just appalling! And I cannot believe that...I don't know, maybe it's because I work in a high school that I would be monitoring whatever the kids are on, at least their Twitter name or Instagram name, it's embarrassing, I mean, and to think that they would purposefully name themselves that and their 600 friends can see it. So to me, a lot of degrading words, especially with the females attacking their character and who they are is huge.

\section{School counselor effectiveness.} School counselor participants all experienced working with students over these types of character assassination, bullying, and harassment that were occurring over text and social media sites, and they struggled with their role in addressing these issues. On one hand, many felt that they were able to help students, especially if the counselor had the support of their administration to come at the issue from a developmental counseling perspective. On the other, they often experienced frustration with students who continued to respond to texts or posts or purposefully engaged in online exchanges with other students, which made matters worse or resulted in physical altercations. Participant Two said:
Usually my advice to...to whoever's getting targeted is "Shut it down. Shut down your Twitter. Shut down your Facebook, don't go on it because if you're not there, then those people won't have access, you know I know that can be painful, but if I can give up Facebook for Lent, you can give it up for a week until this blows over." It's kind of that idea.

Another source of frustration and worry came from participants who could not act on student concerns related to online bullying and harassment. In cases where students had no documentation or proof of online harassment, counselors were frustrated that they did not have the tools to pursue legal recourse or other consequences. Participant Eight said:

We do have students bring stuff in to us, regularly, if they have some that happened on Twitter or Facebook they will bring in the digital...notes of that and they'll bring it in and we'll look at it, but...for the most part, if it's threatening or harming, then yeah...definitely we take it very seriously.

\section{Participant One said:}

And another thing that happens a lot is the kids who tend to claim they're getting bullied on the phone or Facebook have absolutely no proof. They won't print off a page, they will say "I deleted it. I don't have the text messages." So then you're just left with, well that would be evidence and without the evidence, we're just talking. 
Gray areas were not an uncommon experience for school counselors who were helping students with online harassment and bullying. Most participants talked about the "bleed over" between online exchanges that happened off of school property but became part of the students' lives immediately afterwards. Participant Eight mentioned:

That's where we've seen our biggest frustration is that...the kids themselves, if they didn't have that information things would die relatively quickly, but...the problem is, it starts there and then it spills into the school and that's the hard part, just trying to decipher between what to do and what not to do. When you can do something and when you can't do something, so, that part's difficult, so that's the biggest thing.
This frustration was coupled with the fact that school counselors felt that the time dedicated to unraveling the issues surrounding bullying and harassment was taken away from other important duties. Likewise, that frustration was echoed in their perception that students were more interested in engaging in social media than they were in academics. Participant Seven said:

My biggest frustration is the distraction it provides in taking the focus off what really is important and the future. Can it help it? Yeah, it can, but what I've seen is the kids who have the least amount of money, the least amount of supervision, and the least amount of ability are the ones who are most important. And they're so enmeshed in social media that they forget the purpose of school. They don't have

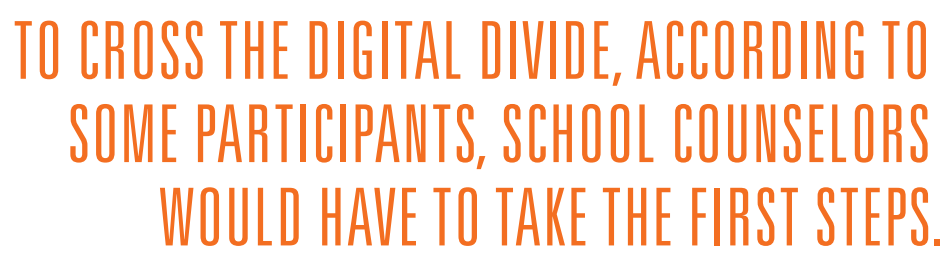

Participant Three said:

And we have had parents come back and say, "Well, this is not an in-school issue," but if it follows the kid to school and if it affects their school day, then we have every right to say it is a school issue because it's come to school and it's an issue at school. So, for the most part, I mean, we'll have an administrator every once in a while, say if there's a mediation issue that didn't work between the two, "You know what, you're the parent, maybe you should take the phone away? I can't take the phone away, I can talk to them, I can counsel them about positive interactions, but I can't take your phone away. So...you do something." the guidance of people to teach them that that's just one form of communication and it's not your whole life. That's my biggest frustration because it's taken the focus off the purpose of school during the day.

\section{Theme 3: Embracing Change}

Regardless of the fears and frustrations the school counselor participants encountered, they all recognized that digital technology was not going away any time soon. In order to cross the digital divide, according to some participants, school counselors would have to take the first steps. Participant Two said:

A couple of my coworkers, they have no idea what a "wall" is. They're like, "Somebody wrote on a wall, I don't understand... was it with a marker? What, what is that?" And so, that communication really breaks down. So if you want to be able to connect with kids on things like that that are giving them problems, you better...you better do it yourself. You know, don't just talk the talk I guess.

Participant Four elaborated on the need for school counselors and other staff members to stay on top of the recent technology and how students use it:

They'll respect you more, they come to you more and trust you more. Something little to you might be really big to them, or something really big to you might be really little to them, and having that...some of these things I'm like, "Holy cow!" but, to them...that didn't bother them, so it's just separating yourself and what your values and beliefs are and realizing that everybody has different values and beliefs. And being there for them if they need you and try to help them as much as possible to be safe and respect them.

Three participants used the word "embrace" when it came to describing the attitude they believed all school counselors should have toward digital technology. These participants believed it would be wise for school counselors to learn about and even use the latest in digital technology, partly because this would help them connect to students but also because technology would drive new applications and software that would support their activities as school counselors. Participant Five said:

There'll be something new and something...I've never, you know, been afraid to play with something and figure it out? You know, either, if you need to. So many teachers they just kinda shudder and, "I don't know how to use..." 
and I, that's never bothered me, so just...don't be afraid of the technology. Embrace it.

Participants also had suggestions for positive ways school counselors could support their students and staff in the use of digital technology including being a good role model and developing and deploying curriculum that addressed student cyber-safety, etiquette, and Internet savvy. School counselors could help students by teaching them how to work with people including social skills, reading nonverbal behaviors, not getting sucked into online social media exchanges, and practicing "unplugging." Participant Three believed school counselors could use digital technology in a positive and impactful way:

I do think we can use social media and technology itself in a positive way and teach good social skills and interpersonal skills. How to use media to do positive things... support a good cause and promote it? Fight for social justice...I mean, you can reach a huge audience out in that cyberworld and so, just as it can have a very domino negative effect, it can also have kind of that positive effect.

\section{DISCUSSION}

Technology use among adolescents is known to be high and an ever-present part of their lives (Lenhart, 2015). The frequent use of technology in students' lives necessitates a focus from the adults around them to understand its use and impact. As anticipated, participants reported that a large percentage of adolescents use social media and text as their most common form of communication with their peers. It was clear from the responses in this study that many school counselors are noticing changes in students today compared to students in the past. Digital natives have created a new culture, a culture that has its own language, values, and customs. Digital immigrants may not always be aware of the intricacies of this culture and struggle to accept its importance in students' lives, yet, as they would for any cultural group, school counselors seek to understand so they can be empathetic to students' interests and help create positive change. The appearance of two value systems would suggest that an inherent cultural divide exists between the school counselors in this study and their students. Most participants recognized students today as different from those a generation ago because of how technology has become interwoven in their lives, creating a new culture-one in which their students are natives and the counselors are immigrants. described educating students on the consequences of negative interactions, teaching students when to speak up with concerns, and promoting the benefits of a balanced life, including screen time and spending time with peers face to face. When considering the role school counselors can play in assisting students, parents, and staff with digital technology, the authors found that this study has several implications for practice.

All of the participants in this study remarked on the negative effects of gossip, rumors, or cyberbullying that occurs through social media with their students. These appeared to be daily occurrences, yet issues with cyberbullying and how to help prevent or stop

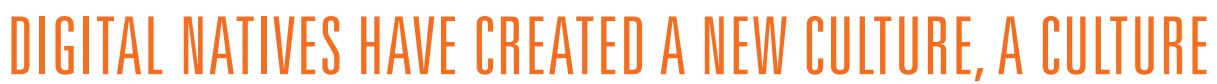 THAT HAS ITS OWN LANGUAGE, VALLES, AND CUSTOMSS.}

Related to this cultural divide, participants discussed their concerns about the lack of students' face-to-face interaction. Participants reported that they had a difficult time imagining nurturing friendships via technology and did not utilize social media as a vehicle for communication during their own formative years. With the increase in communication via social media came concerns that students were sending negative or hurtful comments through text or social media that would not have been said in person. Participants gave many examples of the types of damaging messages they have seen sent back and forth between students within their school buildings. Name calling, sexually inappropriate messages/photos, and even racially charged remarks were brought to the school counselors' office. This aligns with current research that cites disruptions and discipline issues occurring more frequently in the school setting due to negative interactions over social media (Chibbaro, 2007). The participants noted an increase in the number of students needing assistance with issues stemming from online interactions. These school counselors these negative interactions provided a great degree of concern for participants. School counselors are in an ideal position to develop strategies for prevention and intervention of cyberbullying by teaching students how to identify it and by providing methods of reporting it to school staff (Chibbaro, 2007), but many felt frustrated with the limitations of what they are able to do. As issues related to cyberbullying and harassment garner more attention from the media and legal system, schools will be forced to take an active role in preventing these types of negative interactions (through social media) and perhaps include programming that aims to teach students about these behaviors.

The participants in this study reported that their students seek them out for help in resolving issues related to digital technology, and that school counselors are doing their best to assist with the challenges found within social media. As one participant described, identifying the role they play in working through online harassment or helping a student understand the consequences of posting inappropriate photos are a few of the issues facing 
school counselors today. School counselors have the essential role of assisting in students' personal development. Critical elements of that role involve helping students navigate through these difficult situations by problem solving with the student, being a role model, and helping advocate for the students' rights.

\section{IMPLICATIONS FOR SCHOOL COUNSELORS}

Findings from this study suggest several implications for school counselors. First, school counselors are encouraged to seek professional development around technology, if needed; specifically, how to address the challenging situations involving social media as these types of occurrences increase in the school environment. Difficult situations such as students sending harassing texts, inappropriate photos, or impulsive remarks can lead to negative consequences for many young people that could potentially be avoided with more guidance and teaching from educators. To provide this support, educators need their own knowledge base to build from. They may also need to view digital natives as another cultural group that elicits cultural sensitivity and knowledge. School counselors who look at digital natives (or their values and habits) as adverse may need to examine their own biases in order to develop rapport and better empathize with their students. Second, school counselors may want to consider school counseling curricula that connects social skills with online activities and incorporates school/family partnerships in teaching online etiquette. School counselors can support families by providing information about technology and its uses and misuses, which can enable students to interact in electronic forums safely. Third, school counselors may want to consider the increase in cyberbullying and online harassment. They may need to seek additional training and understanding of how to ethically and legally work through these situations. Last, school counselors may wish to be more involved with local school, district, and state policy creation related to appropriate use of technology.

School counselors may be helped by a better understanding of the benefits and hazards of digital media to be able to competently assist their students. As noted by many of the participants, they are utilizing technology, but most likely not all of the social media platforms used by their students. A willingness to learn about the various outlets may help school counselors better assist students as the students seek help from them. School counselors are in a central position to provide information and guidance on both the advantages and drawbacks of technology (Bauman \& Tatum, 2009), yet they may need to seek out opportunities to learn about the digital generation and possibly educate others in their school. As mentioned by the participants in this study, school counselors are not the only ones tackling these issues; teachers, principals, and even parents are looking for ways to help students work through these concerns. Counselors can also educate parents about their involvement with their child's online activities. Blau (2011) recommended that parental involvement include knowing what a child is doing online, paying attention to

\section{SCHOOL COUNSELLORS ARE ENCOURAGED TO SEEK PROFESSIONAL DEVELOPMENT AROUND ... HOW TO ADDRESS THE CHALLENGING SITUATIONS INVOLVING SOCIAL MEDIA.}

their technology, providing guidelines and guidance, and working to view life from the digital native perspective. Parents will also seek out the school counselor for advice on monitoring the digital world in which their children are immersed.

With more professional development, school counselors may learn how to use different types of technology and, more important, learn how their students use them so that they can anticipate and work with problematic situations involving social media. Professional development opportunities may also promote the development of classroom guidance lessons that provide safe introductions to the Internet and social media and teach 21st-century skills (Bauman \& Tatum, 2009). Although some of the participants in this study immersed themselves in the digital world, not all counselors felt this was necessary. Professional development related to social media topics combined with child and adolescent development could be very useful to many practitioners. As many of the participants remarked, the digital revolution is here to stay.

School counselors can play a role in teaching and modeling how to navigate the digital world in a responsible way by providing specific information about cyberbullying, harassment, and school policy to their students through classroom guidance. Within the ASCA Mindsets and Behaviors for Student Success, standards related to social skills and acceptable behaviors that improve interactions between students are also recommended for school counselors to use within their programs (ASCA, 2014). Connecting social skills to online interactions may be something entirely new for students. School counselors can also advocate for victims of cyberbullying and harassment by working with their administrators to develop policies and procedures to ensure students have a way of reporting any problems. Understanding the ethical and legal obligations of these behaviors is important for anyone working with children and adolescents. Many of the participants 
struggled with the role they should play when it comes to handling issues of harassment; having clear procedures in place may lessen this concern.

Last, school counselors may wish to enhance their leadership skills by involving themselves in committees that create policy. As mentioned earlier in regard to cyberbullying, participants reported experiencing a tug-of-war between what was required by school policy and what might be best for the student. Depending upon the school, discussing technology with school leadership may help administrators and other staff better understand students' developmental needs, while school counselors gain more experience with evaluating and creating policy. School counselors may also want to become active in their state organizations and partner with state administration teams to discuss use of technology, discipline, intervention, and policy at the state level.

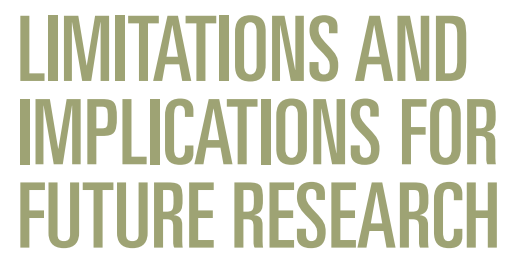

Although generalizability is not a goal of qualitative research (Lincoln \& Guba, 1985), transferability of findings is important in order for readers to identify commonalities in their worlds. The fact that all participants in this study came from one small region may give some readers difficulty in determining whether these results are relevant to their area. Although the authors attempted to understand the school counselor's experience related to working with digital natives, they acknowledge that they cannot assume to understand the students' experience without direct student interviews. A future study that investigates students' experiences may provide valuable insight for school counselors.

Multiple interviews with participants or utilizing a variety of methods might have provided more complex views of the experiences of practicing school counselors and contributed to the results of the study (Rossman \& Rallis, 2003). Furthermore, inviting participants to read the conclusions drawn to verify, elaborate, correct, or extend findings might have also strengthened the credibility of the study (Rossman \& Rallis, 2003). Although interview questions were open ended, a few of the questions may have been interpreted with a negative slant, which possibly could have influenced participants to respond in a biased manner. Last, although the authors completed bracketing of assumptions, it is always possible for researcher bias to interfere with conclusions drawn.

As the digital native population grows, potential areas for research will follow suit. Additional research is needed in recognizing how school counselors can better understand the influences of social media on students' lives so that they may positively impact students' overall development. Research that investigates effective strategies in counseling students related to digital technology could be useful. One potential area for future research includes examining the self-efficacy of school counselors both prior to and after training in social media and the digital native population. Also, examining the relationship between extensive use of technology as an addiction and its relationship to student wellness may be of interest for future work. Last, the impact of parent training on digital citizenship and parents' role in the home in helping their child successfully navigate technology usage may prove beneficial for student well-being.

This study adds to the limited research available on school counseling and the influence of digital technology. It is the school counselor's responsibility to invest time and energy into learning more about the world in which their students are living. Students will continue to walk into school counseling offices with questions and concerns regarding social occurrences that have happened in a digital and relatively unmonitored world. Profes- sional development related to social media could provide opportunities for school counselors to gain a better understanding of digital technology, intervention and prevention strategies, and potential effects on adolescent development. While digital immigrants and digital natives continue to learn as technology continues to develop, the school counseling profession can narrow the gap between fearing the technological unknown and embracing the communication style of a new and beautiful culture of students.

\section{REFERENCES}

American School Counselor Association. (2010). Ethical standards for school counselors. Alexandria, VA: Author.

American School Counselor Association. (2012). The ASCA National Model: A Framework for School Counseling Programs (3rd ed.). Alexandria, VA: Author.

American School Counselor Association. (2014). Mindsets and behaviors for student success: K-12 college- and career-readiness standards for every student. Alexandria, VA: Author.

Barrett, J. (2006). Social networking: A new tech tool and a new security concern for teens and schools. MultiMedia \& Internet@Schools, 13(3), 8-11.

Bauman, S., \& Tatum, T. (2009). Web sites for young children: Gateway to online social networking? Professional School Counseling, 13(1), 1-7. doi:10.5330/PSC.n.2010-13.1

Blau, M. (2011). Learning from digital natives: 6 Surprising benefits. Retrieved from http://www.psychology.today.com/ blog/consequential/strangers/201101/ learningdigital-natives-6-surprisingbenefits?page $=2$

Chibbaro, J. S. (2007). School counselors and the cyberbully: Interventions and implications. Professional School Counseling, 11(1), 65-71. doi:10.5330/PSC.n.2010-11.65

Creswell, J. W. (2013). Qualitative inquiry and research design: Choosing among five approaches. Thousand Oaks, CA: Sage Publications.

Creswell, J.W. (2014). Research design: Qualitative, quantitative, and mixed methods approaches. Thousand Oaks, CA: Sage Publications. 
Englander, M. (2012). The interview: Data collection in descriptive phenomenological human scientific research. Journal of Phenomenological Psychology, 43, 13-35.

doi:10.1163/156916212X632943

Giedd, J. N. (2012). The digital revolution and adolescent brain evolution. Journal of Adolescent Health, 51, 101-105. doi:10.1016/j.jadohealth.2012.06.002

Lenhart, A. (2015). Teens, social media \& technology overview 2015. Report from the Pew Internet \& American Life Project. Retrieved from http://www. pewinternet.org/2015/04/09/teenssocial-media-technology-2015/

Lenhart, A., Madden, M., \& Hitlin, P. (2005). Teens and technology: Youth are leading the transition to a fully wired and mobile nation. Report from Pew Internet \& American Life Project. Retrieved from http://www. pewinternet. org/files/old-media/Files/Reports/2005/ PIP_Teens_Tech_July2005web.pdf.pdf
Lincoln, Y. S., \& Guba, E. G. (1985). Naturalistic inquiry. Beverly Hills, CA: Sage.

Livingstone, S. (2008). Taking risky opportunities in youthful content creation: Teenagers' use of social networking sites for intimacy, privacy and self-expression. New Media Society, 10, 393-411. doi:10.1177/1461444808089415

Oriji, A., \& Efebo, P. I. (2013). New technology, new methodology: The "digital natives" and "digital immigrants" debate. Journal of Educational Review, 6, 237-243.

Palfrey, J., \& Gasser, U. (2008). Born digital. New York, NY: Basic Books.

Patton, M. Q. (2002). Qualitative research \& evaluation methods (3rd ed.). Thousand Oaks, CA: Sage Publications.

Prensky, M. (2001). Digital natives, digital immigrants. On the Horizon, 9(5), 1-5.
Quitney, J., \& Rainie, L. (2010). Millenials will make online sharing in networks a lifelong habit. Report from the Pew Internet \& American Life Project. Retrieved from http://www. pewinternet. org/

Rossman, G. B., \& Rallis, S. F. (2003). Learning in the field: An introduction to qualitative research (2nd ed.). Thousand Oaks, CA: Sage Publications.

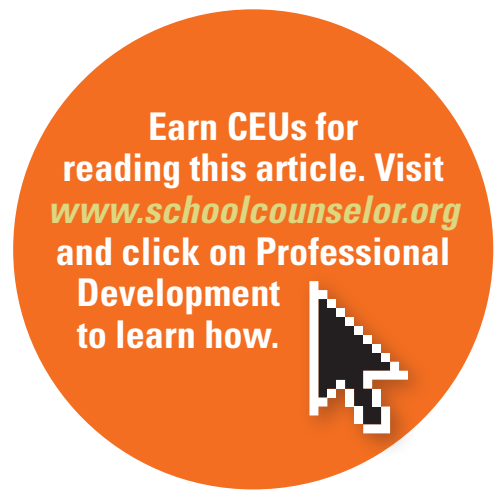

\section{APPENDIX SEMIISTRUCTURED INTERVIELI GUIDE}

1) How often are students coming in to see you regarding issues related to digital technology such as texts, Facebook, Twitter, or something else?

2) Please describe what some of these digital technology issues have involved.

3) What do you feel are some of the positive effects of digital technology?

4) What do you feel are some of the negative effects of digital technology?

5) Does your school currently have any policies related to negative experiences that occur with digital technology?

6) What kinds of digital technology are you personally comfortable using?

7) How prepared do you feel in terms of counseling students related to issues with digital technology?

8) What is your biggest frustration related to high school students' usage of digital technology?

9) What advice do you have for future school counselors related to digital technology?

10) Is there anything else you'd like to add? 